\title{
Concept of 'Central' or 'Axial' Atlantoaxial Instability
}

Atul Goel $\boldsymbol{M C h}^{1}$ iD

${ }^{1}$ Department of Neurosurgery, Lilavati Hospital and Research Center, Mumbai, India

Date of submission: $9^{\text {th }}$ November 2021

Date of acceptance: $18^{\text {th }}$ November 2021

Date of publication: $1^{\text {st }}$ December 2021

\begin{abstract}
The atlantoaxial joint is the most mobile joint of the spine and is most liable to develop instability. Atlantoaxial instability can be identified on observation of facetal alignment on lateral profile imaging, telltale clinical and radiological evidence and by direct observation of instability by manual manipulation of bones during surgery. Central or axial atlantoaxial instability is when there is no abnormal increase in atlantodental interval on dynamic imaging and there is no dural or neural compression by the odontoid process. Understanding and appropriately treating central or axial atlantoaxial instability can have clinical implications.
\end{abstract}

Key words: Atlantoaxial instability, Axial, Central.

\section{Introduction}

$\sim$ raniovertebral junction is masterfully designed and architectured by Nature and caters to both stability and mobility whilst allowing free traverse to critical neural and vascular structures. The atlantoaxial joint is the most mobile joint and occipitoatlantal joint is the most stable joint of the body. Both mobility and stability are the hallmarks of craniovertebral junction. Whilst atlantoaxial joint is the most mobile joint of the body, it is the spinal segment most prone to develop instability. On the other hand, occipitoatlantal instability is an extremely rare clinical situation.

Our analysis of the subject reveals that atlantoaxial instability is an under-diagnosed and undertreated clinical entity. Atlantoaxial instability is relatively common and can be associated with a number of commonly encountered

\section{Access this article online}

Website: https://www.nepjol.info/index.php/NJN

DOI: https://doi.org/10.3126/njn.v18i4.40826

HOW TO CITE

Goel A. Concept of 'Central' or 'Axial' Atlantoaxial Instability. NJNS. 2021;18(4):4-11.

Address for correspondence:

Prof. Atul Goel

Department of Neurosurgery,

Lilavati Hospital and Research Center,

Bandra, Mumbai, India.

E-mail: atulgoel62@hotmail.com

Phone: +91-9819264198

Copyright (C) 2021 Nepalese Society of Neurosurgeons (NESON)

ISSN: 1813-1948 (Print), 1813-1956 (Online)

This work is licensed under a Creative Commons Attribution-Non Commercial 4.0 International License. clinical conditions. This review discusses the clinical issue of CAAD ('central' or 'axial' atlantoaxial dislocation) and analyzes the clinical implications of correct diagnosis and timely surgical treatment. ${ }^{1}$

\section{Atlantoaxial instability}

Atlantoaxial articulation is involved in circumferential movements. Special anatomical peculiarities of the bones of the region facilitate the movements. Transverse process of atlas, spinous process of axis, facets of atlas and axis are the largest and strongest when compared to the rest of the spine. Additionally, the odontoid process presents a special feature to the region. The rostral surface of the facet of atlas that is in proximity to the occipital condyle is remarkably rough and facilitates attachment to strong ligaments of occipitoatlantal joint. On the other hand, the caudal surface of the facet of atlas is relatively smooth. A large majority of muscles of the craniovertebral junction and rest of the spine are located posteriorly or in the extensor compartment and help to maintain 'head on shoulders' and the human standing position throughout life. Essentially the special musculoskeletal anatomical features facilitate stability of the occipitoatlantal articulation and mobility of atlantoaxial articulation. It may not be incorrect to state that craniovertebral junction instability essentially means atlantoaxial instability and craniovertebral junction stabilization essentially refers to atlantoaxial stabilization.

\section{Classification of atlantoaxial instability}

Atlantoaxial instability has been traditionally diagnosed on the basis of abnormal alteration in the atlantodental interval on dynamic images. Atlantodental interval in flexed head position of more than $3 \mathrm{~mm}$ in adults and $5 \mathrm{~mm}$ in children below 5 years of age are indicators of atlantoaxial instability. Neural compression by the odontoid process is also an indicator of unstable 
atlantoaxial joint. In mobile atlantoaxial instability the atlantodental interval reduces to normal on extension of the neck. In 'fixed' or 'partially mobile' or 'partially fixed' atlantoaxial instability, the abnormal atlantodental interval does not reduce or reduces incompletely.,3 Our earlier articles discuss 'rotatory', 'lateral' and 'vertical' atlantoaxial dislocation, their clinical implications and discuss rational surgical strategy. ${ }^{4-6}$

Acute atlantoaxial instability is related to trauma. Severe neck pain and stiffness of muscles of the nape of neck and a range of neurological deficits are the hallmarks of such instability.

Chronic atlantoaxial instability is a relatively common clinical issue, but is frequently not diagnosed or is missed. Natural reparative measures are the hallmarks of chronic atlantoaxial instability. A range of musculoskeletal and neural 'alteration' is introduced by 'Nature' to prevent or delay neurological deficits related to the instability and to protect function and life. ${ }^{7}$ Musculoskeletal alterations include the umbrella term 'basilar invagination'. Klippel Feil alteration, assimilation of atlas, C2-3 fusion, osodontoideum, bifid $\mathrm{C} 1$ and $\mathrm{C} 2$ arches and platybasia can either be present discretely or in association. ${ }^{5,6-11} \mathrm{We}$ earlier discussed short neck, short head and short spine as manifestations of chronic atlantoaxial instability. ${ }^{12}$ Short neck and torticollis and spinal kyphoscoliosis are external physical manifestation. ${ }^{13,14}$ Neural alterations include Chiari formation and syringomyelia. ${ }^{15,16}$ Our earlier articles introduced the terms 'external' syringomyelia and 'external' syringobulbia and discussed similarities in function with syringomyelia and syringobulbia. ${ }^{17}$ Retroodontoid 'pseudotumor' was also identified to be secondary alteration related to atlantoaxial instability and mimicked osteophytes in the subaxial spine. ${ }^{18}$

Our observations suggest that all the secondary musculoskeletal or neural alterations when present in isolation or in cohort are indicators of presence of atlantoaxial instability. ${ }^{19}$ The musculoskeletal and neural alterations attempt to make the spinal cord traverse a smaller and stretch free course and the fluid excess in the region serves to float the cord away from the odontoid process and avoid compression. ${ }^{19}$ The other observation was that even when the secondary alteration is seemingly 'pathological' it has a natural 'protective' function and is 'reversible' following atlantoaxial stabilization. Considering these views, we prefer to label craniovertebral junction 'abnormalities' or 'anomalies' as craniovertebral junction 'alterations'. Similarly, we prefer to label Chiari 'malformation' as Chiari 'formation' and identify tonsillar herniation into foramen magnum as Natures 'airbag' that is introduced in situ in the presence of potential or manifest atlantoaxial instability. ${ }^{20,21}$

Alternative parameters of diagnosis of atlantoaxial instability: In the year 2007, we identified that 'listhesis' of facet of atlas over the facet of axis, simulating lumbosacral listhesis, is the primary point of initiation and progression of basilar invagination..$^{22}$ As the understanding of instability of craniovertebral junction has progressed over the years, we identified additional indicators of atlantoaxial instability. ${ }^{23}$ Lateral profile imaging (CT scan/ MRI or plain radiographs) of the craniovertebral junction in neutral head position is adopted.

Type 1 atlantoaxial instability: The facet of atlas is dislocated anterior to the facet of axis. (Figure 1) Such instability is more often present in acute or relatively acute clinical situation. The symptoms are also relatively acute and the secondary 'natural' alterations or 'protective' maneuvers are relatively less prominent or are absent.

Type 2 atlantoaxial instability: The facet of atlas is dislocated posterior to the facet of axis. (Figure 2) Such a form of atlantoaxial instability is usually present in chronic or longstanding atlantoaxial instability.

Type 3 atlantoaxial instability: The facets of atlas and axis are in alignment and instability is identified on the basis of presence of secondary natural protective maneuvers. (Figure 3) Additionally, instability is confirmed on intraoperative manipulation of the spinous process of axis and other bones of the region.

CAAD: In both Type 2 and Type 3 atlantoaxial instability, the atlantodental interval may not be abnormal and there may not be any evidence of neural or dural compression. Such atlantoaxial instability is referred to as CAAD. ${ }^{23}$

Basilar invagination: On the basis of understanding of CAAD, it was identified that both Group A and Group $\mathrm{B}$ are secondary to 'chronic' atlantoaxial instability. ${ }^{8-10}$, 24, 25 More often Type 2 and 3 and less often Type 1 atlantoaxial instability is the point of pathogenesis of basilar invagination. Type 1 atlantoaxial instability is more often associated with Group A basilar invagination. . $^{825}$

Chiari formation and syringomyelia: The term tonsillar 'herniation' mimicks the term uncal 'herniation' and hence a sense of urgency in the treatment has prevailed. Traditionally, both Chiari formation and syringomyelia have been identified to be 'pathological' in nature and have been considered to be 'space occupying lesions' that result in neural compromise or compression. Foramen magnum decompression and syrinx fluid drainage techniques have been described to surgically deal with these situations. On the basis of our understanding, chronic or longstanding atlantoaxial instability is the point of pathogenesis of both Chiari formation and syringomyelia. Both these events are secondary, are naturally protective and are potentially reversible following the surgical procedure that involves atlantoaxial stabilization. Clinical symptom of pain in the nape of neck seem to be more related to atlantoaxial instability than to alterations in the intracranial pressures as has been previously speculated. ${ }^{26}$ Symptoms of sleep 


\section{Goel et al}

apnea, breathing disturbances, voice alterations and breathless on exertion were identified to be related to atlantoaxial instability. ${ }^{27}$ On the basis of our analysis we advocated the efficacy of atlantoaxial fixation in resolution of the symptoms and reversal of tonsillar herniation and reduction in the size of syringomyelia. ${ }^{15,28}$ The resolution of clinical symptoms is immediate and motor evoked potential can reverse even during operation after the screws for atlantoaxial fixation are tightened. ${ }^{29}$

Syringomyelia is often associated with Chiari formation. Like other natural alterations that can be present in isolation (idiopathic syringomyelia) or in cohort, syringomyelia when present in association with Chiari or without it, can be associated with atlantoaxial instability and will need atlantoaxial stabilization. ${ }^{16}$ Direct manipulation of the syrinx cavity is necessarily avoided. Dramatic resolution of syrinx can be observed after atlantoaxial stabilization.

Cervical spondylotic myelopathy: Cervical spinal degeneration is often identified in the lower cervical spinal region. Degeneration at the craniovertebral junction is rarely identified. We observed that it is not disc water reduction, but it is 'vertical' spinal instability related to weakness of muscles that partake in the standing human position are the nodal point of pathogenesis of spinal degeneration. Buckling of the posterior longitudinal ligament and ligamentum flavum, osteophyte formation and reduction in the disc space are all secondary to vertical spinal instability and are 'protective' natural response to instability. Intervertebral disc herniation or prolapse is either a result of or results in spinal instability. Our concept is that it is not neural compression or deformation but it is spinal instability that is the cause of symptoms. ${ }^{30}$ As instability is the primary issue 'only' stabilization is the treatment of single or multiple level spinal degeneration related radiculopathy or myelopathy. Following stabilization of the spinal segment, all the secondary issues can potentially reverse. Atlantoaxial joint is the most mobile joint and is the most likely joint to develop instability and related issues of spinal degeneration. CAAD is more often associated in such cases. Upper cervical spinal degeneration, multi-level cervical spinal degeneration or cases presenting with severe myelopathy, more often than not have atlantoaxial instability. Identification and treatment of atlantoaxial instability is critical for clinical recovery. ${ }^{31}$ On the other hand, ignoring atlantoaxial instability can lead to incomplete recovery of symptoms or even clinical worsening.

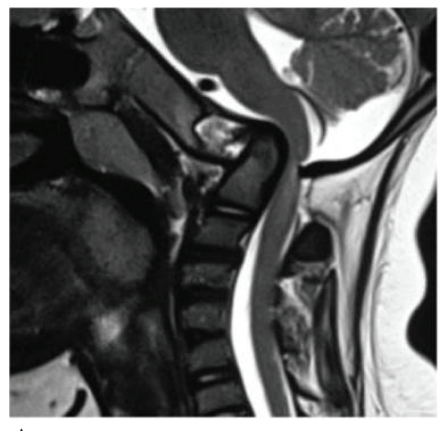

A

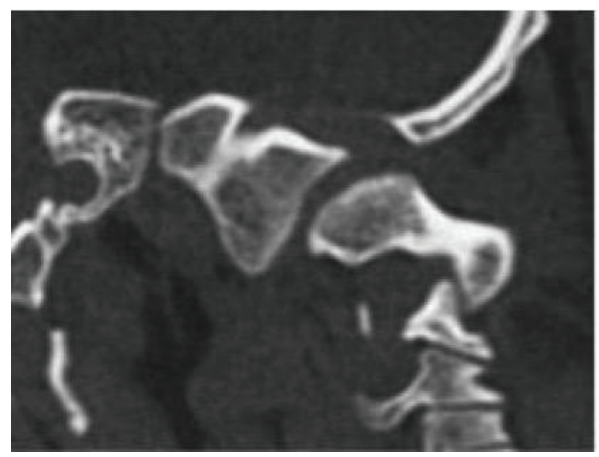

$\mathrm{D}$

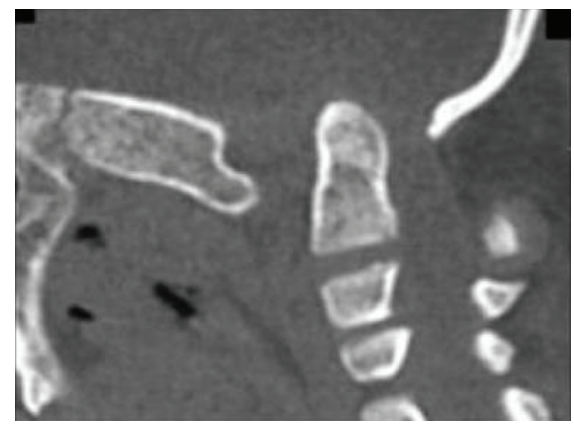

B

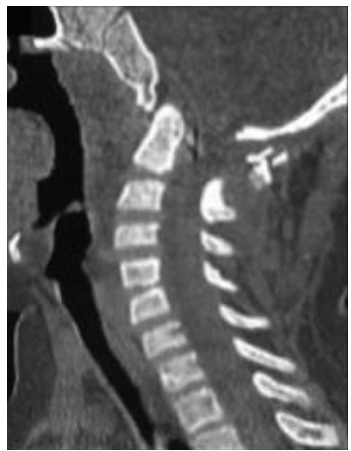

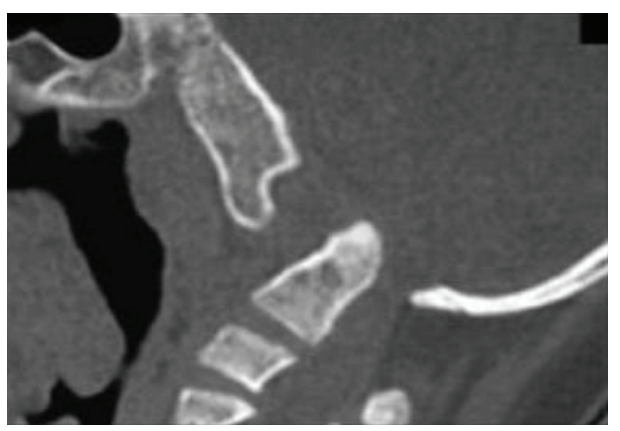

C

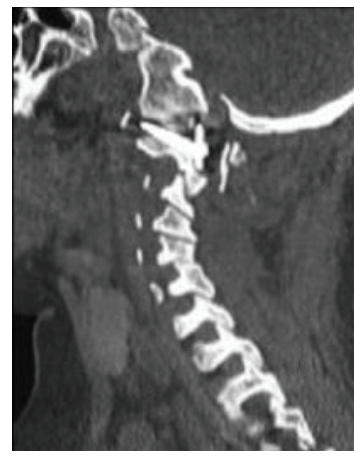

F

Figure 1: (A) T2 weighted MRI image showing Group A basilar invagination and external syringomyelia. (B) Sagittal cut of CT scan with the head in flexion showing Group A basilar invagination and assimilation of atlas. (C) CT Scan with the head in extension showing vertical atlantoaxial instability. (D) Sagittal CT scan with the cut through the facets showing Type 1 atlantoaxial instability. (E) Post-operative CT scan showing craniovertebral re-alignment. (F) Post-operative CT scan showing the implant. 


\section{'Central' or 'Axial' Atlantoaxial Instability}
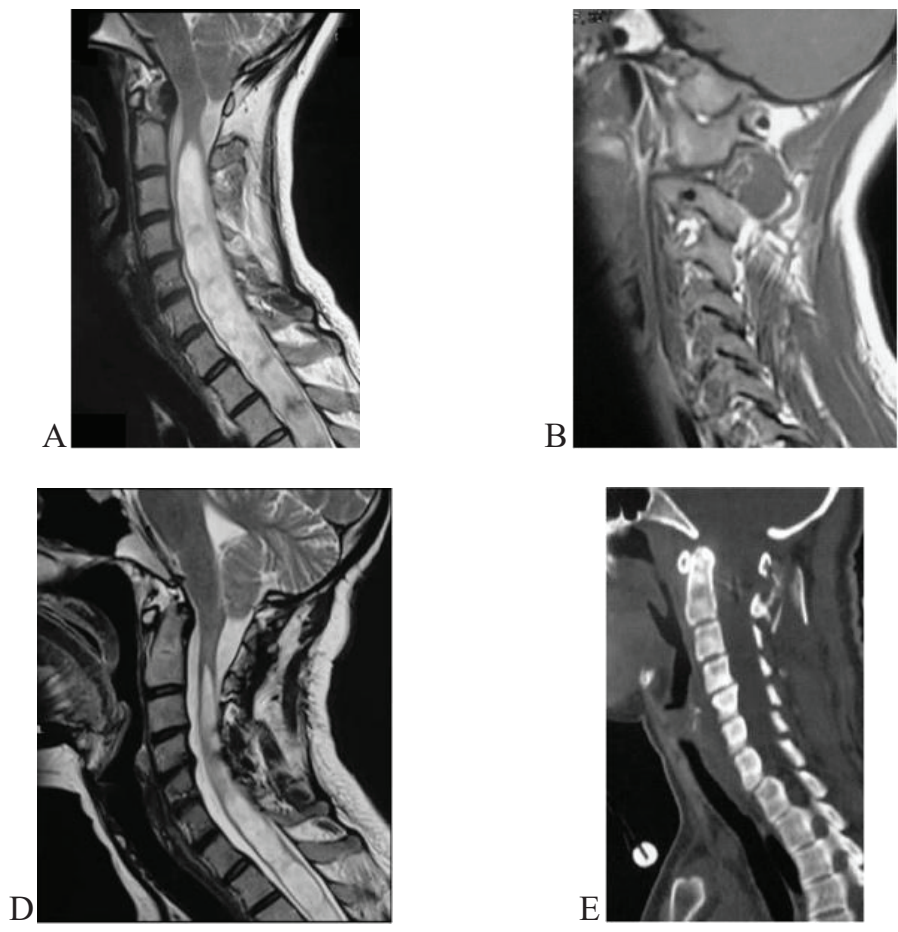
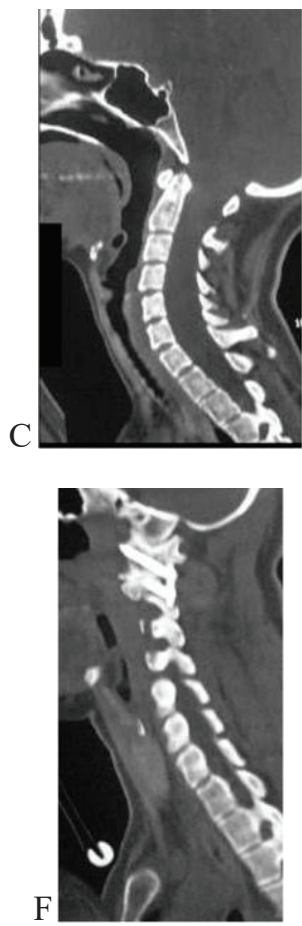

Figure 2: (A) T2 weighted sagittal MRI showing Chiariformation and syringomyelia. (B) Sagittal MRI image with cut through the facets showing Type 2 atlantoaxial instability. (C) Sagittal CT scan showing no bone anomaly at the craniovertebral junction. The atlantodental interval is normal. (D) Post-operative MRI showing a reduction in the syringomyelia.(E) Postoperative CT image. (F) Post-operative CT scan showing the implant.
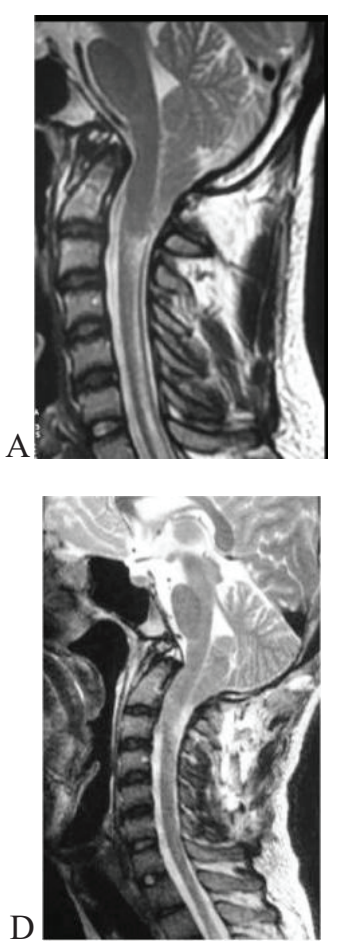
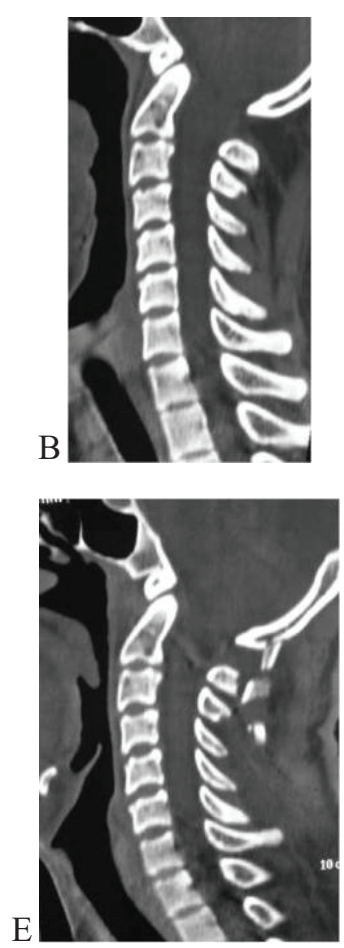
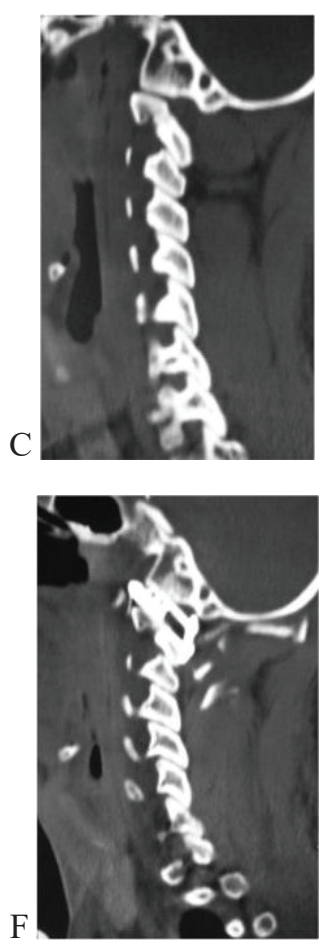

Figure 3: (A) T2 weighted sagittal MRI showing Group B basilar invagination, Chiari formation and syringomyelia. (B) Sagittal CT scan showing Group B basilar invagiation and assimilation of atlas. The atlantodental interval is normal. (C) Sagittal CT image with cut through the facets showing Type 3 atlantoaxial instability. The facets are in alignment. (D) Post-operative MRI showing a reduction in the syringomyelia. (E) Post-operative CT image showing the fixation. (F) Postoperative CT scan showing the implant. 
Ossification of posterior longitudinal ligament (OPLL) can result in myelopathy. Treatment of OPLL has been done conventionally by decompression of the neural structures by removal of bone, soft tissues and OPLL by multiple level corpectomy. Indirect decompression is done by laminectomy or laminoplasty. Our concept is that like spinal degeneration, OPLL is secondary to vertical spinal instability. 'Only' spinal stabilization without any form of decompression is the treatment. ${ }^{32} \mathrm{CAAD}$ is more often than not associated in such cases and needs to be addressed.

Hirayama disease: Exact etiology of Hirayama disease is not clearly identified and has been debated. We identified that CAAD and sub-axial cervical spinal instability can be a cause of Hirayama disease.
Multisegmental cervical spinal stabilization that includes atlantoaxial joint can form a rational form of treatment. ${ }^{33}$

CAAD as a discrete clinical entity: CAAD can be an independent clinical entity and a cause of cervical myelopathy. ${ }^{34}$ High degree of suspicion that is based on clinical findings and radiological observations can guide towards the correct diagnosis. Presence of unusual cervical lordotic curvature, bone fusions, bifid arch of atlas and other telltale evidence can guide the surgeon towards the diagnosis of CAAD. Identification and treatment of CAAD can lead to relief from disabling symptoms (Figures 4 and 5). ${ }^{34,35}$

Essentially, we observe that a range of clinical conditions can be associated with CAAD. It is essential to understand and evaluate instability on the basis of tell-tale clinical and radiological guides and treat accordingly.
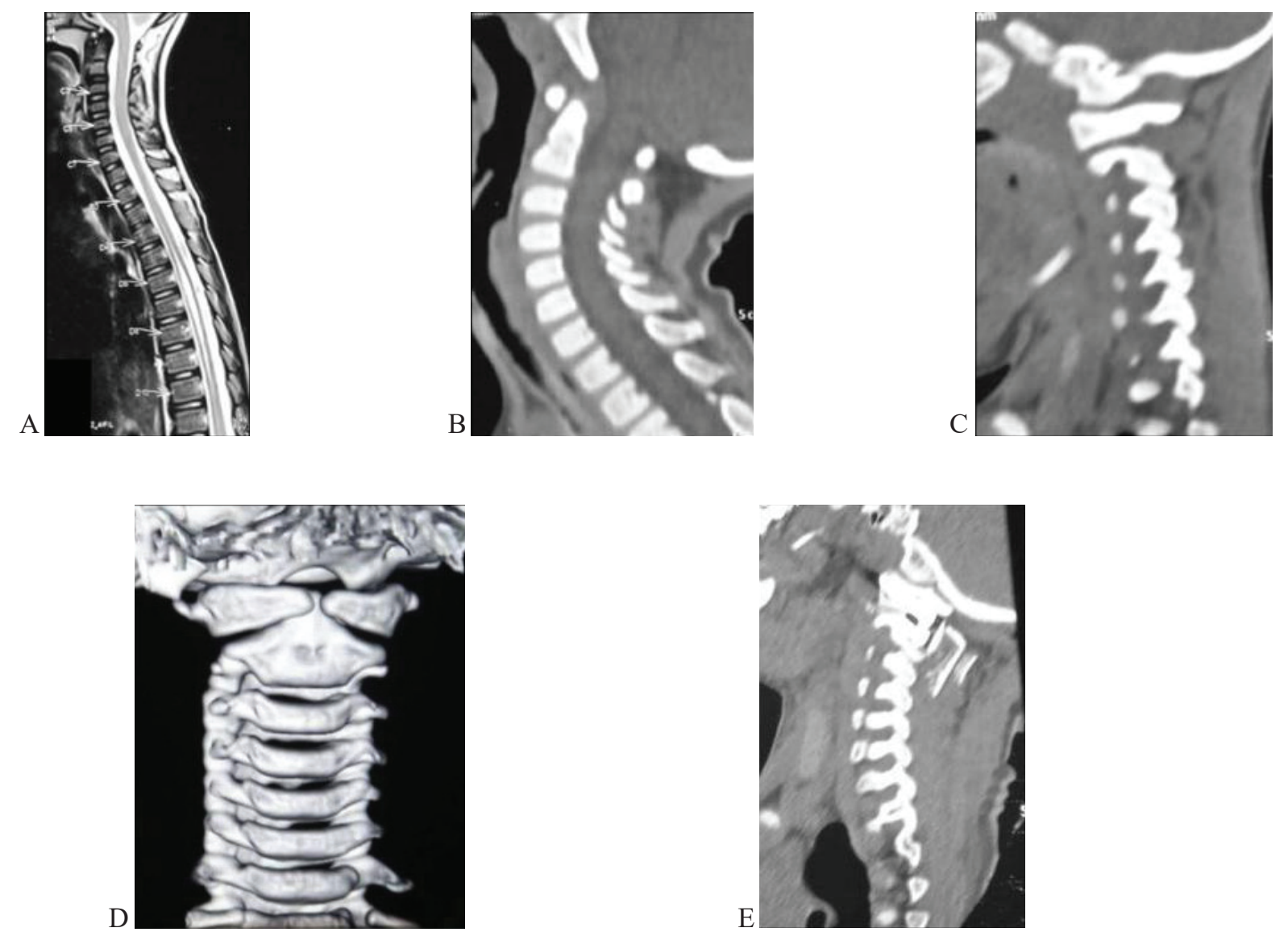

Figure 4: (A) T2 weighted sagittal MRI showing syringomyelia. There is no compression at the craniovertebral junction. (B) Sagittal CT scan showing no change in the atlantodental interval. (C) Sagittal CT image with cut through the facets showing Type 3 atlantoaxial instability. The facets are in alignment. (D) $3 D$ reconstructed image of CT scan showing bifid arches of atlas. (E) Post-operative CT scan showing the implant. 


\section{'Central' or 'Axial' Atlantoaxial Instability}
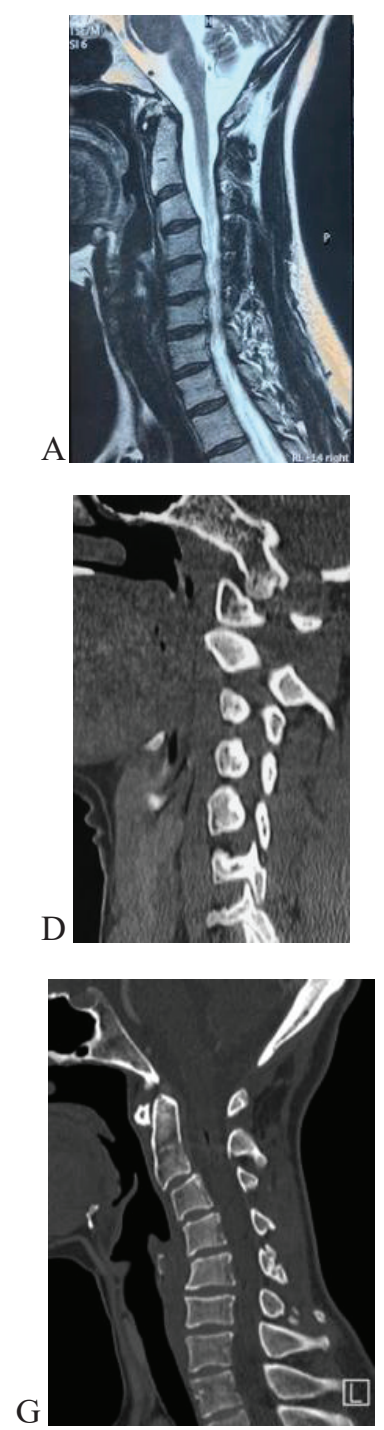
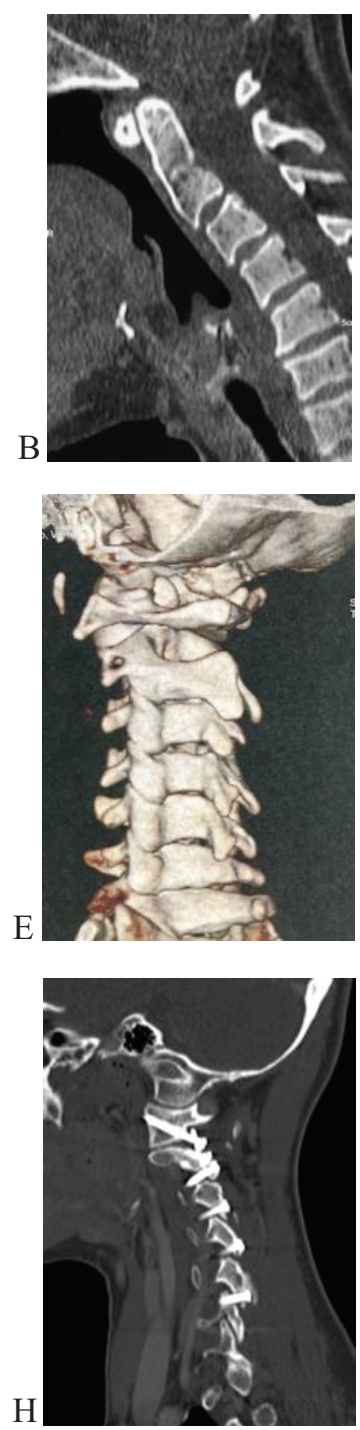
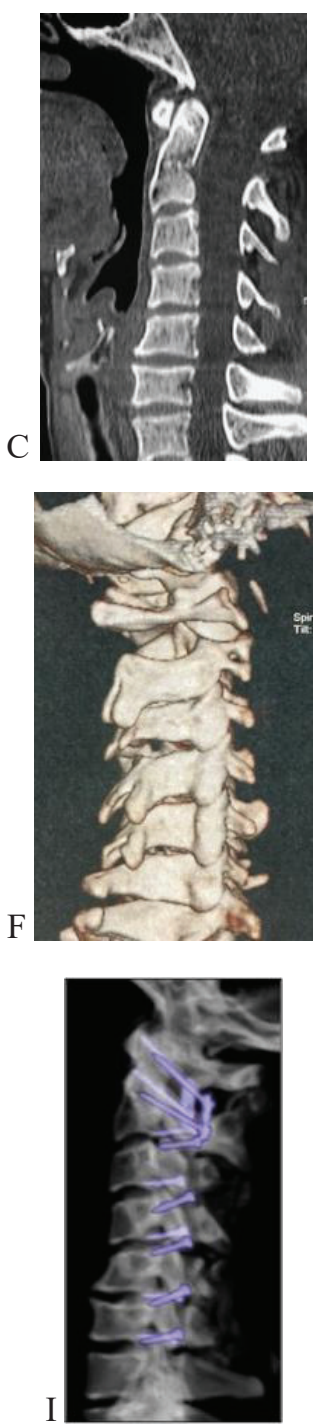

Figure 5: (A) T2 weighted MRI image showing cervical kyphosis, multilevel cervical degenerative changes. The craniovertebral junction is normal. (B) Sagittal cut of CT scan with the head in flexion showing no change in the atlantodental interval. (C) CT scan with the head in extension. (D) Sagittal CT scan with the cut through the facets showing Type 2 atlantoaxial instability. (E) 3D reconstructed CT scan showing normal alignment of facets of atlas and axis on one side. (F) 3D reconstructed CT scan of the contralateral facets showing Type 2 atlantoaxial instability. (G) Post-operative CT scan. (H) Post-operative CT scan showing the implants. (I) Post-operative X-ray showing the atlantoaxial and subaxial fixation.

\section{Conflict of Interest: None \\ Source(s) of support: None}

\section{References}

1. Goel A. A Review of a New Clinical Entity of 'Central Atlantoaxial Instability’: Expanding Horizons of Craniovertebral Junction Surgery. Neurospine. 2019; 16(2):186-194. https://doi.org/10.14245/ ns. 1938138.069
2. Goel A, Laheri VK. Plate and screw fixation for atlanto-axial dislocation. (Technical report). Acta Neurochir (Wien). 1994; 129:47-53. https://doi. org/10.1007/BF01400872

3. Goel A, Desai K, Muzumdar D. Atlantoaxial fixation using plate and screw method: a report of 160 treated patients. Neurosurgery. 2002; 51:1351-1357. https:// doi.org/10.1097/00006123-200212000-00004

4. Goel A, Shah A. Atlantoaxial facet locking: treatment by facet manipulation and fixation. Experience in 14 
cases. J Neurosurg Spine. 2011 Jan;14(1):3-9. https:// doi.org/10.3171/2010.9.SPINE1010

5. Goel A, Nadkarni T, Shah A, Ramdasi R, Patni N. Bifid Anterior and Posterior Arches of Atlas: Surgical Implication and Analysis of 70 Cases. Neurosurgery. 2015; 77(2):296-305; discussion 305-6. https://doi. org/10.1227/NEU.0000000000000761

6. Goel A, Shah A, Rajan S. Vertical mobile and reducible atlantoaxial dislocation. Clinical article. J Neurosurg Spine. 2009; 11(1):9-14. https://doi. org/10.3171/2009.3.SPINE08927

7. Goel A, Shah A. Reversal of longstanding musculoskeletal changes in basilar invagination after surgical decompression and stabilization. J Neurosurg Spine. 2009; 10:220-227. https://doi. org/10.3171/2008.12.SPINE08499

8. Goel A, Jain S, Shah A. Radiological Evaluation of 510 Cases of Basilar Invagination with Evidence of Atlantoaxial Instability (Group A Basilar Invagination). World Neurosurg. 2018; 110:533-543. https://doi.org/10.1016/j.wneu.2017.07.007

9. Goel A, Nadkarni T, Shah A, Sathe P, Patil M. Radiologic Evaluation of Basilar Invagination Without Obvious Atlantoaxial Instability (Group B Basilar Invagination): Analysis Based on a Study of 75 Patients. World Neurosurg. 2016; 95:375-382. https://doi.org/10.1016/j.wneu.2016.08.026

10. Goel A, Sathe P, Shah A. Atlantoaxial Fixation for Basilar Invagination without Obvious Atlantoaxial Instability (Group B Basilar Invagination): Outcome Analysis of 63 Surgically Treated Cases. World Neurosurg. 2017; 99:164-170. https://doi. org/10.1016/j.wneu.2016.11.093

11. Goel A, Patil A, Shah A, Dandpat S, Rai S, Ranjan S. Os Odontoideum: Analysis of 190 Surgically Treated Cases. World Neurosurg. 2020;134:e512-e523. https://doi.org/10.1016/j.wneu.2019.10.107

12. Goel A. Short neck, short head, short spine, and short body height - Hallmarks of basilar invagination. J Craniovertebr Junction Spine. 2017;8(3):165-167. https://doi.org/10.4103/jcvjs.JCVJS_101_17

13. Goel A, Vutha R, Shah A, Dharurkar P, Jadhav N, Jadhav D. Spinal Kyphoscoliosis Associated with Chiari Formation and Syringomyelia 'Recovery' Following Atlantoaxial Fixation: A Preliminary Report and Early Results Based on Experience with 11 Surgically Treated Cases. World Neurosurg. 2019; 125:e937-e946. https://doi.org/10.1016/j. wneu.2019.01.212

14. Goel A, Vutha R, Shah A, Rai SKR. Rotatory atlantoaxial dislocation presenting as spinal kyphoscoliosis. J Craniovertebr Junction Spine. 2021; 12(1):99-101. https://doi.org/10.4103/jcvjs. jcvjs_6_21
15. Goel A. Is atlantoaxial instability the cause of Chiari malformation? Outcome analysis of 65 patients treated by atlantoaxial fixation. J Neurosurg Spine. 2015; 22:116-127. https://doi.org/10.3171/2014.10. SPINE14176

16. Shah A, Sathe P, Patil M, Goel A. Treatment of "idiopathic" syrinx by atlantoaxial fixation: Report of an experience with nine cases. J Craniovertebr Junction Spine. 2017; 8(1):15-21. https://doi. org/10.4103/0974-8237.199878

17. Goel A. External syrinx-introduction of a new term. J Craniovertebr Junction Spine. 2016; 7(4):191-192. https://doi.org/10.4103/0974-8237.193253

18. Goel A, Darji H, Shah A, Prasad A, Hawaldar A. RetroOdontoid and Retro-C2 Body Pseudotumor, Pannus, and/or Cyst. A Study Based on Analysis of 63 Cases. World Neurosurg. 2021; S1878-8750(21)00526-X. https://doi.org/10.1016/j.wneu.2021.03.155

19. Goel A. Indicators of atlantoaxial instability. J Craniovert Jun Spine 2021; 21:103-6. https://doi. org/10.4103/jcvjs.jcvjs_55_21

20. Goel A. Is Chiari a "formation" or a "malformation?" J Craniovertebr Junction Spine. 2017; 8(1):1-2. https://doi.org/10.4103/0974-8237.199881

21. Goel A. Is Chiari malformation nature's protective "air-bag"? Is its presence diagnostic of atlantoaxial instability? J Craniovertebr Junction Spine. 2014; 5:107-109. https://doi.org/10.4103/09748237.142302

22. Kothari M, Goel A. Transatlantic Odonto-Occipital Listhesis: the so-called basilar invagination. Neurol India. 2007 Jan-Mar;55(1):6-7. https://doi. org/10.4103/0028-3886.30416

23. Goel A. Goel's classification of atlantoaxial 'facetal' dislocation. J Craniovertebr Junction Spine. 2014; 5:15-19. https://doi.org/10.4103/0974-8237.135206

24. Goel A, Bhatjiwale M, Desai K. Basilar invagination: a study based on 190 surgically treated patients. J Neurosurg. 1998;88(6):962-8. https://doi. org/10.3171/jns. 1998.88.6.0962

25. Goel A. Treatment of basilar invagination by atlantoaxial joint distraction and direct lateral mass fixation. J Neurosurg Spine. 2004;1(3):281-6. https:// doi.org/10.3171/spi.2004.1.3.0281

26. Goel A. Suboccipital pain in Chiari formation: Its cause and significance. J Craniovertebr Junction Spine. 2018;9(4):221-222. https://doi.org/10.4103/ jcvjs.JCVJS_117_18

27. Goel A, Prasad A, Shah A, Gore S, Dharurkar P. Voice Quality Affection as a Symptom of Chiari Formation. World Neurosurg. 2019;121:e296-e301. https://doi. org/10.1016/j.wneu.2018.09.099

28. Goel A, Jadhav D, Shah A, Rai S, Dandpat S, Vutha R, Dhar A, Prasad A. Chiari 1 Formation 
Redefined-Clinical and Radiographic Observations in 388 Surgically Treated Patients. World Neurosurg 2020; 141:e921-e934. https://doi.org/10.1016/j. wneu.2020.06.076

29. Shah A, Patil A, Vutha R, Thakar K, Goel A. Recovery of Transcranial Motor Evoked Potentials After Atlantoaxial Stabilization for Chiari Formation: Report of 20 Cases. World Neurosurg. 2019;127:e644-e648. https://doi.org/10.1016/j. wneu.2019.03.236

30. Goel A. Not neural deformation or compression but instability is the cause of symptoms in degenerative spinal disease. J Craniovertebr Junction Spine. 2014; 5(4):141-2 https://doi.org/10.4103/09748237.167850

31. Goel A. Role of Subaxial Spinal and Atlantoaxial Instability in Multisegmental Cervical Spondylotic Myelopathy. Acta Neurochir Suppl. 2019; 125:7178. https://doi.org/10.1007/978-3-319-62515-7_11
32. Goel A, Grasso G, Shah A, Rai S, Dandpat S, Vaja T, Jadhav D, Jadhav N. "Only Spinal Fixation" as Surgical Treatment of Cervical Myelopathy Related to Ossified Posterior Longitudinal Ligament: Review of 52 Cases. World Neurosurg. 2020; 140:556-563. https://doi.org/10.1016/j.wneu.2020.03.198

33. Goel A, Dhar A, Shah A. Multilevel Spinal Stabilization as a Treatment for Hirayama Disease: Report of an Experience with Five Cases. World Neurosurg. 2017; 99:186-191. https://doi. org/10.1016/j.wneu.2016.11.143

34. Goel A, Dhar A, Shah A, Jadhav D, Bakale N, Vaja T, Jadhav N. Central or Axial Atlantoaxial Dislocation as a Cause of Cervical Myelopathy: AReport of Outcome of 5 Cases Treated by Atlantoaxial Stabilization. World Neurosurg. 2019; 121:e908-e916. https://doi. org/10.1016/j.wneu.2018.10.009

35. Goel A. Occiput, $\mathrm{C} 1$ and $\mathrm{C} 2$ instrumentation. In Winn: Youmans and Winn Neurological Surgery, 7th edition, Elsevier 2017, Philadelphia pp 8967 - 8994 